Z. klin. Chem. u. klin. Biochem.

10. Jg. 1972 , S. $12-16$

\title{
Ein UV-Test zur Messung der $\alpha$-Amylase-Aktivität in Serum und Urin
}

\author{
Von H.-W. Schrwara
}

\author{
Aus der Medizinischen Klinik (Chefarzt: Prof. Dr. F. Heepe) des Städtischen Krankenbauses Stade
}

(Eingegangen am 23. August 1971)

Es wird ein auf dem Maltose-Nachweis beruhender UV-Test zur Messung der $\alpha$-Amylase-Aktivität ${ }^{1}$ ) in Serum und Urin beschrieben. $\alpha$-Glucosidase und Hexokinase dienen als Hilfsenzyme, Glucose-6-phosphat-Dehydrogenase ist Indikatorenzym, NADPH Meßgröße. Die Meßergebnisse sind gut reproduzierbar bei Messungen in Serie (Serum: VK $=3,6 \%$ bei $\bar{x}=229$ U/1; Urin: VK $=4,4 \%$ bei $\bar{x}=1320 \mathrm{U} / \mathrm{l}$ ) und bei Messungen von Serie zu Serie (Serum: VK $=6,5 \%$ bei $\overline{\mathbf{x}}=150 \mathrm{U} / 1$; Urin: VK $=11,3 \%$ bei $\overline{\mathrm{x}}=1594 \mathrm{U} / 1$ ). Die Normalverte wurden für Urin mit 10-530 U/1, für Serum mit 24-163 U/1 ermittelt. Wegen verminderter Präzision der Meßergebnisse erfordern 4,0 g/l überschreitende Glucosekonzentrationen im Untersuchungsmaterial Entfernung der Glucose durch Dialyse oder Gelfiltration. Mit unterschiedlichen Stärkepräparaten zeigt $\alpha$-Amylase im UV-Test dieselben Aktivitäten. Wesentlich geringer ist die Maltosebildung aus Amylose.

\section{A UV-test for the measurement of $\alpha$-amylase activity in serum and urine}

A UV-test is described for the determination of $\alpha$-amylase ${ }^{1}$ ) activity in serum and urine, based on the measurement of maltose. $\alpha$-gluccsidase and hexokinase act as auxillary enzymes, glucose-6-phosphate dehydrogenase is the indicator enzyme and NADPH is measured. The results show good reproducibility in serial measurements (serum: VC $=3.6 \%$ at $\overline{\mathrm{x}}=229 \mathrm{U} / \mathrm{l}$; urine: VC=4.4\% at $\overline{\mathrm{x}}=1320 \mathrm{U} / \mathrm{l}$ ) and in measurements from series to series (serum: $V C=6.5 \%$ at $\bar{x}=150 \mathrm{U} / 1$; urine: $\mathrm{VC}=11.3 \%$ at $\overline{\mathrm{x}}=1594 \mathrm{U} / 1$ ). The normal values obtained for urine were $10-530 \mathrm{U} / \mathrm{l}$, for serum $24-163 \mathrm{U} / \mathrm{l}$. Glucose concentrations greater than $4.00 \mathrm{~g} / \mathrm{l}$ of test material decrease the precision of the results, so the glucose must be removed by dialysis or gel filtration. Using the UV-test, $\alpha$-amylase shows the same activity with different starch preparations; the formation of maltose from amylose is essentially much slower.

Seit Wohlgemuth seine Methode zum Nachweis der $\alpha$-Amylase angegeben hat (1), sind zahlreiche andere Verfahren ausgearbeitet worden mit dem Ziel, durch größere Empfindlichkeit der Messung und vereinfachte Analytik der Bedeutung der $\alpha$-Amylase-Bestimmung für die klinische Diagnostik und den Anforderungen neuzeitlicher Laboratoriumsdiagnostik besser gerecht zu werden. Die saccharogenen Verfahren fanden wegen ihres analytischen Aufwandes (lange Inkubationszeiten, Farbreaktionen zum Nachweis der reduzierenden Gruppen bei $100^{\circ}$ ) und wegen des Interferierens höherer Glucosekonzentrationen keinen Eingang in die RoutineDiagnostik (2-4). Neuere Methoden, die auf der Freisetzung gefärbter Dextrine aus mit einem Farbstoff gekoppelten Substraten basieren, weisen diese Nachteile nicht mehr auf und sind für die Routine gut geeignet $\left.(5,6)^{2}\right)$. Die amyloklastischen Verfahren sind trotz der Einfachheit in der Durchführung wegen ihres kleinen Meßbereiches nicht zur Methode der Wahl geworden (7).

Der hier mitgeteilte UV-Test beruht auf dem Nachweis der durch $\alpha$-Amylase aus Stärke gebildeten Maltose. Durch $\alpha$-Glucosidase wird Maltose zu Glucose hydrolysiert, die durch Hexokinase phosphoryliert und in der anschließenden Glucose-6-phosphat-Dehydrogenasereaktion durch NADPH-Bildung gemessen wird. Die Methode weist den geringen analytischen Aufwand der

1) Enzyme: $\alpha$-Amylase $=\alpha$-1,4-Glucan 4-Glucanhydrolase (EC 3.2.1.1); $\alpha$-Glucosidase $=\alpha$-D-Glucosid Glucohydrolase (EC 3.2.1.20); Hexokinase = ATP: D-Hexose 6-phosphotransferase (EC 2.7.1.1); Glucose-6-phosphat-Dehydrogenase = DGlucose-6-phosphat: NADP Oxydoreduktase (EC 1.1.1.49). 2) Als "DyAmyl" (Gödecke AG, Berlin) und "Phadebas“" (Deutsche Pharmacia, Frankfurt/M.) im Handel. amyloklastischen Verfahren bei großem Meßbereich, guter Präzision und vertretbaren Kosten auf. $\mathrm{Da}$ ein genau definiertes Reaktionsprodukt als $\mathrm{Ma} \beta \operatorname{der} \alpha$ Amylase-Aktivität dient, ist eine exakte Formulierung der Internationalen Einheit entsprechend den Empfehlungen der Enzymkommission der IUB möglich (8). Einer Anwendung der $\alpha$-Amylase-Bestimmung im UV-Test in der Routine steht entgegen, daß bei höheren Glucosekonzentrationen im Untersuchungsmaterial die Glucose durch Dialyse oder Gelfiltration entfernt werden muß. Eine vorläufige Mitteilung der AmylaseBestimmung im UV-Test erfolgte an anderer Stelle (9).

\section{Methodik}

\section{Reagenzien}

$\alpha$-Amylase vom Schwein (Merck Nr. 1326), $\alpha$-Glucosidase (Boehringer, Mannheim), lösliche Stärke p. a. (Merck Nr. 1252), Sephadex G-25 fine (Deutsche Pharmacia, Frankfurt/M.), Amylose wurde der Testpackung „ $\alpha$-Amylase“ der Firma E. Merck, Darmstadt, entnommen.

Glucose-Reagenz für den UV-Test: $0,25 \mathrm{M}$ Triäthanolamin; $2,5 \mathrm{~mm}$ $\mathrm{MgSO}_{4} ; 10 \mathrm{mM}$ ATP, $0,8 \mathrm{~mm}$ NADP; $6,8 \mu \mathrm{g} / \mathrm{ml} \geqq 1,0 \mathrm{U} / \mathrm{ml}$ Glucose-6-phosphat-Dehydrogenase; $6,8 \mu \mathrm{g} / \mathrm{ml} \geqq 1,0 \mathrm{U} / \mathrm{ml}$ Hexokinase. Verwendet wurden die Reagenzien der Testpackung "Glucose-UV-Test" (Boehringer, Mannheim).

\section{Substrat}

4proz. lösliche Stärke p. a. in 0,25M Phosphat-Puffer pH 6,88; $0,05 \mathrm{M} \mathrm{NaCl} . \mathrm{Zu} 500 \mu \mathrm{l}$ dieser Lösung wurden vor Testbeginn $20 \mu \mathrm{l}(10 \mathrm{mg} / 2 \mathrm{ml})$ oder $50 \mu \mathrm{l}(2 \mathrm{mg} / \mathrm{ml}) \alpha$-Glucosidase (Boehringer) gegeben (= Puffer-Substrat-Lösung).

\section{Untersucbungsmaterial}

Für die Normalwertbestimmungen wurden Urine und Seren von Patienten verwendet, bei denen gastroenterologische Erkrankungen nicht bekannt waren. Sofern die gleichzeitig durchgeführte Bestimmung mit dem amyloklastischen Verfahren über dem 
Normbereich liegende Werte ergab, wurden die nach dem UVTest gemessenen Aktivitäten für die Normalwcrtberechnung verworfen. Bei den Urinen handelt es sich vorwiegend um 8-Stdn.-Sammelurine.

\section{Probenvervabrung}

Die zu untersuchenden Urine und Seren sowie die Kontrollproben wurden z. T. eingefroren, z. T. bei $+4^{\circ}$ ohne Aktivitätsverlust über mehrere Wochen aufbewahrt.

Standard-Test

Die Durchführung des Standard-Tests ist in Tabelle 1 als Arbeitsanleitung wiedergegeben. Die photometrischen Messungen erfolgten mit einem mechanisierten Meßplatz mit Drucker.

rab. 1

Durchführung des Standard-Tests. Volumenangaben in Mikroliter

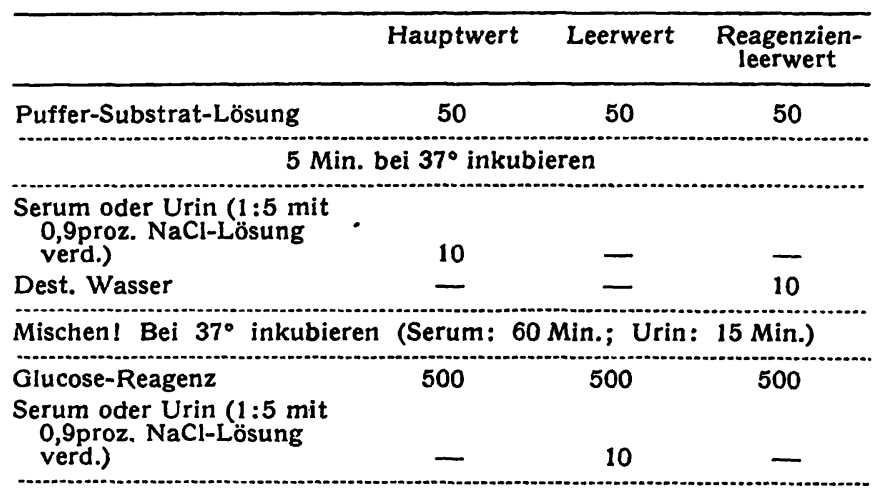

Mischen! Nach 15 minütiger Inkubation bei Raumtemperatur werden Haupt- und Leerwert gegen den Reagenzienleerwert bei $366 \mathrm{~nm}$ gemessen.

Serum: $\Delta E \cdot 707=U / 1$, Urin: $\Delta E \cdot 2830=U / 1$.

Bei Aktivitäten über $2000 \mathrm{U} / 1$ für die Urin- und über $500 \mathrm{U} / 1$ für die Serum-Amylase (jeweils unkorrigierte Werte) muß die Untersuchung an den weiter verdünnten Proben vorgenommen werden.

\section{Amyloklastische $\alpha$-Amylase-Bestinumung}

Es wurde die Testpackung „ $\alpha$-Amylase“ der Fa. Dr. Heinz Haury, München, unter Benutzung der beiliegenden Testrorschrift verwendet (10).

\section{Saccharogene $\alpha$-Amylase-Bestimmung}

Die Dinitrosalicylsäure-Methode wurde eingesetzt (4).

Enzym-Einbeit

Eine Internationale Einheit $(U)$ ist diejenige $\alpha$-Amylase-Aktivität, die unter den Bedingungen des Standard-Tests $1 \mu \mathrm{Mol}$ Maltose pro Min. bildet.

\section{Dialyse}

Zur Dialyse wurde „Visking“-Dialysierschlauch Type 8/32 der Fa. Serva Entwicklungslabor, Heidelberg, verwendet.

\section{Gelfiltration}

Gelfiltrationen wurden mit Sephadex G-25 fine in kleinen Säulen $(1,2 \times 4,0 \mathrm{~cm})$ durchgeführt. Das $\mathrm{Gel}$ wurde vor Gebrauch in 0,9proz. $\mathrm{NaCl}$-Lösung suspendiert. Fraktionierungen erfolgten von Hand. Nach Spülen mit 0,9proz. NaCl-Lösung kann eine Säule mehrfach wieder verwendet wcrden.

\section{Qualitatskontrolle}

Bei allen Serien wurden Serum- und Urinproben bekannter Amylase-Aktivität als Kontrollen mitgeführt. Die Ergebnisse der so ethaltenen Präzisionskontrolle sind im Abschnitt „Reproduzierbarkeit" wicdergegeben.

\section{Ergebnisse und Diskussion}

\section{Die Meßtechnik}

Im ersten Teil des Tests hydrolysiert die zu messende $\alpha$-Amylase Stärke während einer bestimmten Inkubationszeit; die gebildete Maltose wird durch $\alpha$-Glucosidase zu Glucose gespalten. Der zweite Teil dient dem Glucosenachweis. Die Probelösung durchläuft im Leerwert, der im übrigen die gleiche Zusammensetzung wie der Hauptwert hat, nur die Glucosenachweisreaktion. Damit werden alle nicht durch $\alpha$-Amylase bedingten Extinktionszunahmen im UV-Bereich (Glucose im Untersuchungsmaterial, Maltosebeimengung der Stärke, $\alpha$-Amylase als mögliche Fremdaktivität $\operatorname{der} \alpha$-Glucosidase) korrigiert.

Das Verfahren erfüllt die an einen Enzym-Test gestellte Forderung von Proportionalität zwischen gemessener Aktivität und Inkubationszeit einerseits und gemessener Aktivität (hier: Maltosebildung) und eingesetzter Enzymmenge (hier: $\mu \mathrm{g} \alpha$-Amylase) andererseits (Abb. 1).

In dem früher mitgeteilten Verfahren (9) wurde durch Fällung der $\alpha$-Amylase mit Perchlorsäure die enzymatische Stärkehydrolyse gestoppt. Hier wird die Inkubationszeit durch Zugabe des Reagenz für den Glucosenachweis beendet und damit der Test wesentlich vereinfacht. Die Zugabe des Glucose-Reagenz bedingt eine Verdünnung der $\alpha$-Amylase-Aktivität, $\operatorname{der} \alpha$-Glucosid-

\section{Abb. 1}

Abhängigkeit der Maltosebildung a) von der eingesetzten Enzymmenge bei unterschiedlichen Inkubationszeiten $(15,30,60 \mathrm{Min}$.)

b) von der Inkubationsżeit. Eingesetzte Amylase-Aktivität: 3,38 mU/Test
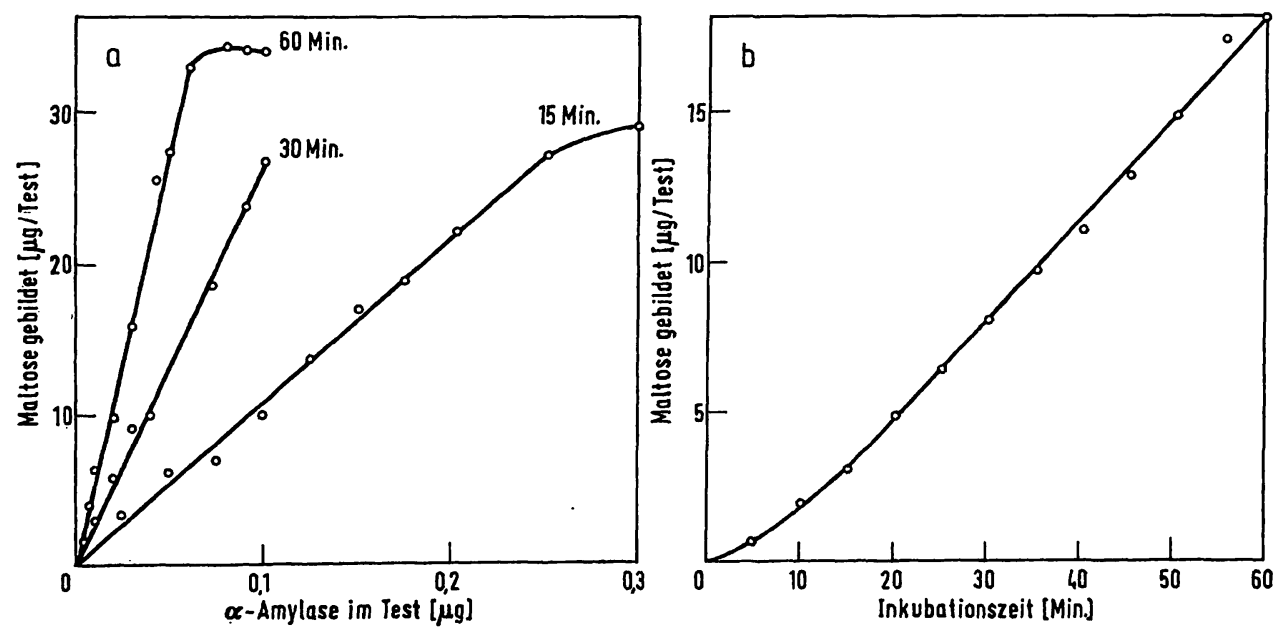

Z. klin. Chem. u. klin. Biochem. / 10. Jahrg. 1972 / Heft 1 



Abb. 2

Maltosehydrolyse bzw. -freisetzung unter den Bedingungen des Hauptund Leerwertes

a) Maltosehydrolyse unter den $\cdot \mathrm{Be}$ dingungen des Hauptwertes $(\bullet-\bullet)$. $\mathrm{Zu}$ der Puffer-Substrat, $\alpha$-Glucosidase und Maltose enthaltenden Lösung wurden sofort $500 \mu \mathrm{l}$ Glucose-Reagenz gegeben und die Maltosespaltung gemessen $(0-0)$ (= Leerwertbedingungen)

b) Maltosefreisetzung durch $0,2 \mu \mathrm{g}$ $\alpha$-Amylase unter den Bedingungen des Hauptwertes ( $\bullet-\bullet)$. Steigende Mengen $\alpha$-Amylase $(0,2 ; 2,0 ; 20 \mu \mathrm{g})$ wurden zu der Puffer-Substrat, $\alpha$-Glucosidase und $500 \mu \mathrm{l}$ GlucoseReagenz enthaltenden Lösung gegeben und die Maltosebildung gemessen $(0-0) \quad(=$ Leerwertbedingungen) ase und der Stärke im Test um den Faktor 9,3, so daß die während der Glucosenachweisreaktion noch meßbare Maltosebildung im Vergleich zur Maltosebildung und -hydrolyse unter den Bedingungen des Hauptwertes gering ist. Meßtechnisch wird also mit der Zugabe des Glucose-Reagenz die Inkubationszeit für die $\alpha$-Amylase beendet. Die, nach Zugabe des Glucose-Reagenz noch nachweisbare geringe Maltosebildung erfolgt in Hauptund Leerwert gleichmäßig und wird durch die erwähnte Korrektur des Haupt- gegen den Leerwert eliminiert. Diese Vorstellungen werden durch die in Abbildung 2 dargestellten Versuche belegt.

Bei der Zusammensetzung des Tests wurden hinsichtlich Stärke- und $\mathrm{NaCl}$-Konzentration die Empfehlungen in der neueren Literatur berücksichtigt $(3,7)$. Ebenso wurde der Phosphat-Puffer nach Literaturangaben ausgewählt (4). Die optimale $\alpha$-Glucosidase-Konzentration wurde durch Variation der $\alpha$-Glucosidase-Konzentration im Test ermittelt. Die für den Standard-Test angegebene Konzentration wird für ausreichend erachtet, da weitere Zugabe von $\alpha$-Glucosidase nicht zum Nachweis höherer $\alpha$-Amylase-Aktivitäten führt. Durch einen Maltosewiederfindungsversuch wurde außerdem geprüft, ob unter den Bedingungen des Standard-Tests (15 Min. Inkubationszeit) Maltose quantitativ nachgewiesen wird (Abb. 3). Bis etwa $25 \mu \mathrm{g}$ Maltose im Test ist die Wiederfindung quantitativ, das entspricht recht gut dem direkten Meßbereich der $\alpha$-Amylase (vgl. Abb. 1).

Es wurden verschiedene Stärkepräparationen sowie Amylose als Substrate eingesetzt. Tabelle 2 zeigt, daß bei den verschiedenen Stärkepräparationen kein wesent-

Tab. 2

Messung der $\alpha$-Amylase-Aktivität bei der Verwendung unterschiedlicher Substrate. Angegeben sind die Mittelwerte von Vierfach-Belicher Substrate. Angegeben sind die $M i t$
stimmungen

\begin{tabular}{lc}
\hline Substrat & $\begin{array}{c}\text { gemessene } \\
\text { a-Amylase } \\
\text { Aktivität } \\
\text { (U/1) }\end{array}$ \\
\hline Stärke löslich DAB 6 & 1660 \\
Stärke löslich p. a. & 1680 \\
Stärke löslich nach ZuLkowskY & 1687 \\
Amylose & 359 \\
\hline
\end{tabular}

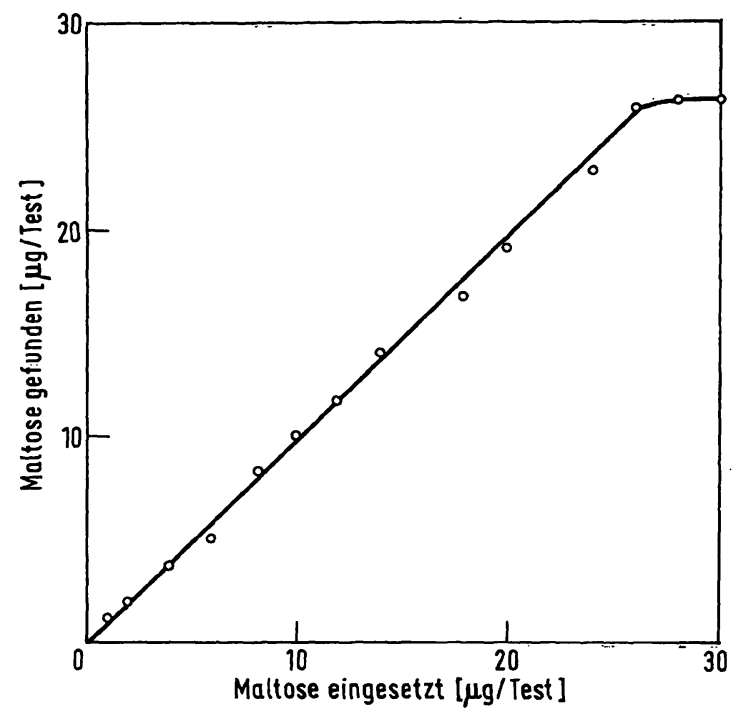

Abb. 3

Maltosewiederfindungsversuch

licher Unterschied besteht, während mit Amylose die Aktivität nur etwa $20 \%$ beträgt.

\section{Reproduqierbarkeit}

Die Reproduzierbarkeit der Ergebnisse wurde eingehend für Serum- und Urin-Amylase in Serie, von Serie zu Serie und in Gegenwart von Glucose untersucht. Ein Teil der Ergebnisse ist in Tabelle 3 zusammengefaßt.

Der Einfluß der Glucose im Untersuchungsmaterial auf die Präzision der Meßergebnisse wurde untersucht. Einem Serum mit einer $\alpha$-Amylase-Aktivität im oberen

Tab. 3

Reproduzierbarkeit der Meßergebnisse für die Serum- und UrinAmylase bei verschiedenen Aktivitäten in Serie und von Serie zu Serie

\begin{tabular}{|c|c|c|c|c|c|}
\hline & & 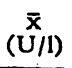 & $n$ & $\stackrel{s}{s}$ & $\begin{array}{l}\text { V.K } \\
(\%)\end{array}$ \\
\hline $\begin{array}{l}\text { Serum-Amylase } \\
\text { Urin-Amylase }\end{array}$ & In Serie & $\begin{array}{r}229 \\
94 \\
348 \\
1320\end{array}$ & $\begin{array}{l}10 \\
10 \\
20 \\
24\end{array}$ & $\begin{array}{l}8,3 \\
5,7 \\
37 \\
58\end{array}$ & $\begin{array}{r}3,6 \\
6,1 \\
10,5 \\
4,4\end{array}$ \\
\hline Serum-Amylase & \multirow{2}{*}{$\begin{array}{l}\text { Von Serie } \\
\text { zu Serie }\end{array}$} & 150 & 9 & 9,8 & 6,5 \\
\hline Urin-Amylase & & 1594 & 15 & 181 & 11,5 \\
\hline
\end{tabular}


Normbereich und einem zweiten mit einer etwas über dem Normbereich liegenden Aktivität wurde Glucose in verschiedenen Konzentrationen 1,$5 ; 2,6 ; 3,0 ; 4,4 ; 5,8$; $10,5 \mathrm{~g} / \mathrm{l})$ zugesetzt. Die $\alpha$-Amylase-Aktivität wurde für jeden Glucose-Konzentrationsbereich in Doppelbestimmungen analysiert; Mittelwert, Standardabweichung und Variationskoeffizient der bei 1,5 bis $5,8 \mathrm{~g}$ Glucose/l gefundenen $\alpha$-Amylase-Aktivitäten wurden ermittelt (Tab. 4). Bei dem Serum mit erhöhter Amylase-Aktivi-

Tab. 4

Präzision der Meßergebnisse in Gegenwart steigender Glucosekonzentrationen bei unterschiedlichen Amylase-Aktivitäten. Die bei 10,5 $\mathrm{g}$ Glucose/I bestimmteri Amylase-Aktivitäten blieben bei der Berechnung von $\bar{x}$, s und VK unberücksichtigt

\begin{tabular}{|c|c|c|c|c|c|c|}
\hline$\underset{(\mathrm{g} / 1)}{\text { Glucose }}$ & $\underset{\substack{\alpha-A m y l a s e \\
(U / 1)}}{\text { Serum } 1}$ & $\begin{array}{l}\text { VK } \\
\text { (\%) }\end{array}$ & $\mathrm{n}$ & $\underset{\substack{\text { Serum } \\
\text { (Umylase } \\
\text { (U/l) }}}{2}$ & $\begin{array}{l}\text { VK } \\
(\%)\end{array}$ & $\mathrm{n}$ \\
\hline $\begin{array}{r}1,5 \\
2,6 \\
3,0 \\
4,4 \\
5,8 \\
10,5\end{array}$ & $\begin{array}{c}230 \\
234 \\
218 \\
219 \\
240 \\
224 \\
242 \\
224 \\
255 \\
257 \\
(160) \\
(140)\end{array}$ & $\cdot 3,6$ & 10 & $\begin{array}{r}106 \\
96 \\
104 \\
106 \\
119 \\
97 \\
120 \\
100 \\
124 \\
131 \\
(141) \\
(86)\end{array}$ & $\begin{array}{l}6,1 \\
8,0\end{array}$ & $\begin{array}{l}10 \\
10\end{array}$ \\
\hline $\begin{array}{l}\overline{\mathbf{x}} \\
\mathbf{s} \\
\mathbf{V K}\end{array}$ & $\begin{array}{c}234 \\
14 \\
6,0\end{array}$ & & & $\begin{array}{c}109 \\
12 \\
11,0\end{array}$ & & \\
\hline
\end{tabular}

tät wurde mit einem VK von $6 \%$ trotz z. T. hoher Glucosekonzentrationen eine gute Präzision erzielt. Wesentlich schlechter reproduzierbar waren die Meßergebnisse bei dem Serum mit niedriger AmylaseAktivität ( $\mathrm{VK}=11 \%$, Tab. 4). Finen weiteren Eindruck von dem Einfluß hoher Glucosekonzentrationen auf die Präzision vermitteln die bei unterschiedlichen Glucosekonzentrationen bestimmten Variationskoeffizienten (Tab. 4). Noch in Gegenwart von 4,4 g Glucose/l wird in dem Serum mit erhöhter Amylase-Aktivität (Serum 1) eine gute Präzision gefunden (VK=3,6\%, $\mathrm{n}=10$ ). Bei geringerer Amylase-Aktivität (Serum 2) wird die Präzision durch hohe Glucosekonzentrationen allerdings stark herabgesetzt ( $\mathrm{VK}=19,5 \%$ ). Zusammenfassend kann gesagt werden, daß die Methode auch in Gegenwart der im Serum vorkommenden erhöhten Glucosekonzentrationen brauchbare Ergebnisse liefert, insbesondere, wenn man berücksichtigt, $\mathrm{da} ß$ meistens erst mehrfach über die Norm erhöhte Amylase-Aktivitäten klinische Relevanz besitzen. Bei höheren Ansprüchen an die Meßgenauigkeit müßte die Glucose durch eines der beschriebenen Verfahren aus dem Untersuchungsmaterial entfernt werden.

Die Verhältnisse im Urin wurden nicht gesondert untersucht, da Urin wie Serum 1:5 verdünnt wird. Brauchbare Ergebnisse bei glucosehaltigem Harn sind also nur zu erwarten, wenn die Glucosurie $4 \mathrm{~g} / 1$ nicht überschreitet. Anderenfalls ist eine vorherige Glucoseabtrennung erforderlich.

\section{Entfernung von Glucose aus dem Untersuchungsmaterial}

Es wurde gezeigt, daß die Methode auch in Gegenwart pathologisch erhöhter Glucosekonzentrationen im Serum noch zuverlässige Ergebnisse liefert. Da bei Diabetikern aber mit die Serum-Glucosekonzentrationen weit überschreitenden Glucosurien $z u$ rechnen ist, wurden die folgenden Versuche an Urinen mit extrem hohem Glucosegehalt $(100 \mathrm{~g} / \mathrm{l})$ durchgeführt.

1. Dialyse: Durch 2stündige Dialyse des 1:5 mit dest. Wasser verdünnten Urins gegen fließendes Leitungswasser konnten aus einem Urin mit einer Ausgangskonzentration von $110 \mathrm{~g}$ Glucose/1 bzw. $23 \mathrm{~g}$ Glucose 1198,8 bzw. $98,6 \%$ der Glucose entfernt werden, ohne daß eine Veränderung der Amylase-Aktivität, gemessen mit dem amyloklastischen Verfahren, beobachtet werden konnte.

2. Gelfiltration: Zwei verschiedene Verfahren wurden geprüft. Einmal wurde ein kleines Volumen des glucosehaltigen Urins ( $100 \mathrm{~g}$ Glucose/l) auf die Sephadex-Säule gegeben, mit 0,9 proz. NaCl-Lösung eluiert und das Eluat fraktioniert (Einzelheiten s. Methodik). Man erhält eine gute Abtrennung der Glucose (Abb. 4). Allerdings ist die Amylase im Eluat stark verdünnt. Für die Routine geeigneter ist das zweite Verfahren, bei dem mit 0,9 proz. NaCl-Lösung verdünnter Urin $(100 \mathrm{~g}$ Glucose/1) kontinuierlich aufgetragen wird. Nach $2,5 \mathrm{ml}$ Vorelution erscheint die $\alpha$-Amylase in den nächsten $0,5 \mathrm{ml}$ praktisch glucosefreiem Eluat in der aufgegebenen Aktivität (Abb.4). Die Abtrennung der Glucose würde wahrscheinlich auf einfachere Weise mittels
Abb. 4

Entfernung von Glucose aus dem Untersuchungsmaterial durch Gelfiltration

a) Auftragen eines kleinen Probevolumens $(100 \mu \mathrm{l}=320 \mathrm{mU} \alpha=$ Amylase $+10 \mathrm{mg}$ Glucose), Elution mit 0,9proz. NaCl und Fraktionierung

b) Kontinuierlicher Durchlauf des mit 0,9 proz. $\mathrm{NaCl} 1: 5$ verdünnten Urins. Fraktionierung des Eluats. Die Amylase-Aktivităt des aufgetragenen Urins betrug vor der Verdánnung 2280 U/l, die Glucosekonzentration $100 \mathrm{~g} / \mathrm{l}$
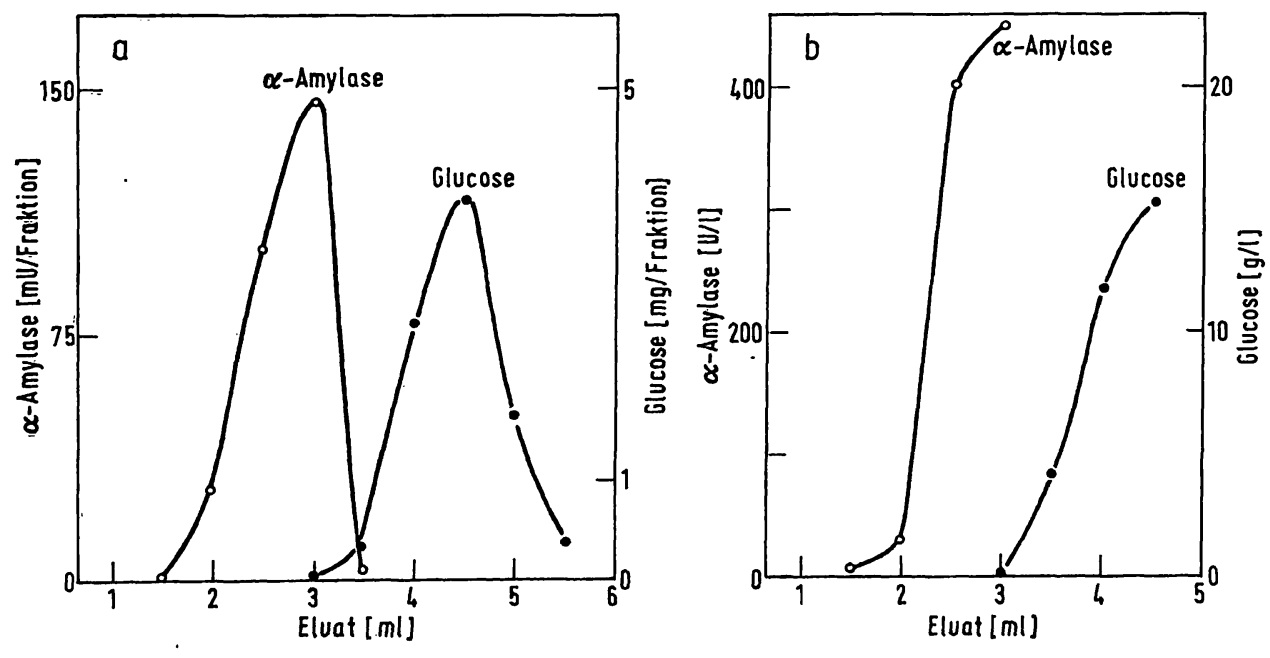
polymer gebundener Glucoseoxydase gelingen, die durch Zentrifugation oder Filtration schnell wieder aus der Lösung entfernt werden könnte und damit den auf einer Glucosebestimmung basierenden Enzym-Test zum Nachweis der $\alpha$-Amylase nicht stören. Mit einer jetzt im Handel exhältlichen unlöslichen Glucoseoxydase ${ }^{3}$ ) fehlen noch eigene Erfahrungen.

\section{Normaliverte}

Für die Urin-Amylase wurde eine Normalverteilung gefunden. Bei $\bar{x}=270 \mathrm{U} / 1$ und $\mathrm{s}=130 \mathrm{U} / 1$ ist der Normalbereich $\overline{\mathrm{x}}= \pm 2 \mathrm{~s}$ zwischen 10 und $530 \mathrm{U} / 1$ anzunehmen. Die Aktivitäten der Amylase im Serum zeigten eine log-normale Verteilung. Der Normalbereich liegt zwischen $\overline{\mathrm{x}}-2 \mathrm{~s}=24 \mathrm{U} / \mathrm{l}$ und $\overline{\mathrm{x}}+2 \mathrm{~s}=163 \mathrm{U} / \mathrm{l}$ bei einem Mittelwert von $\bar{x}=62 \mathrm{U} / 1$. Es wurden jeweils 50 Urine und Seren untersucht.

\section{Erböbte $\alpha$-Amylase-Aktivitäten}

Serum- und Urin-Amylase-Bestimmungen wurden bei einigen Fällen akuter Pankreatitis und Parotitis durchgeführt. Tabelle $5 \mathrm{faßt}$ die Ergebnisse zusammen.

3) ENZITE-Glucoseoxidase (Miles-Seravac, Lausanne).
Tab. 5

Urin- und Serum-Amylase bei akuter Pankreatitis und Parotitis

\begin{tabular}{|c|c|c|}
\hline & Akute Pankreatitis & Parotitis \\
\hline $\begin{array}{c}\text { Urin-Amylase (U/l) } \\
\text { (Extremwerte) } \\
\overline{\mathbf{x}}\end{array}$ & $\underset{8240}{180-22800}$ & $1253-2740$ \\
\hline $\begin{array}{c}\text { Serum-Amylase (U/1) } \\
\text { (Extremwerte) } \\
\overline{\mathbf{X}} \\
n\end{array}$ & $\underset{5}{350-4820}$ & - \\
\hline
\end{tabular}

\section{Vergleich mit anderen Amylase-Bestimmungen}

Vergleichende Untersuchungen wurden mit einer amyloklastischen und einer saccharogenen Amylasebestimmung durchgeführt $(4,10)$. Die Ergebnisse sind in Abbildung 5 wiedergegeben. Die Aktivitäten der $\alpha$-Amylase im UV-Test und der saccharogenen Methode liegen im direkten Meßbereich, während die mit dem amyloklastischen Verfahren gemessenen Aktivitäten, sofern sie über 6250 Somogrr-Einheiten/l liegen, an 10 fach verdünntem Material bestimmt werden mußten. Daraus erklärt sich die größere Streuung oberhalb 6250 ScIMOGYI-Einheiten/1.

Der Fa. Boehringer, Mannheim, danke ich für die kostenlose Überlassung von $\alpha$-Glucosidase, Herrn Dr. BENDE von der Fa. Deutsche Pharmacia, Frankfurt/M. für die Beratung bei der Gelfiltration und die Arbeitsproben Sephadex.
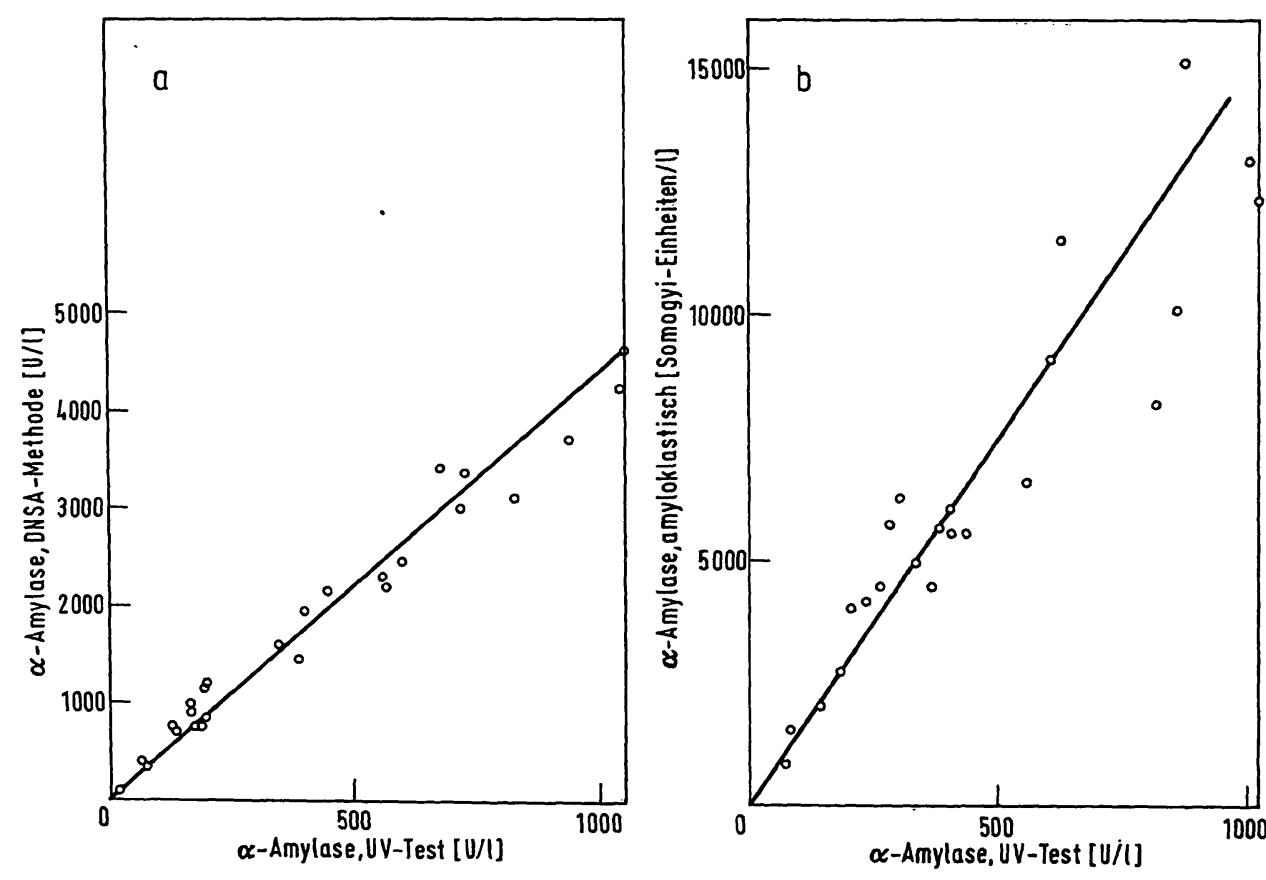

Literatur
Abb. 5

Vergleich der $\alpha$-Amylase im UVTest mit einem saccharogenen (a) und einem amyloklastischen (b) Verfahren. DNSA = Dinitrosalicylsäure
1. Wofilgemuth, J., Biochem. Z. 9, 1 (1908). - 2. Henry, R. J. und N. Chiamori, Clin. Chem., New York 6, 434 (1960). 3. Lorentz, K. und D. Oltmanns, Med. Lab. 23, 25 (1970). 4. Rick, W. und H. P. Stegrauer, in: U. Bergmeyer (Herausg.) „Methoden der enzymatischen Analyse", Verlag Chemie, Weinheim/Bergstr., S. 848 (1970). - 5. BABSON, A. L., S. TENNEY und R. Megraw, Clin. Chem., New York 16, 39 (1970). - 6. Ceska, M., B. Brown und K. Birath, Clin. Chim. Acta, Amsterdam 26,
445 (1969). - 7. Lorentz, K., A. Zander und J. Adiung, diese Z. 7, 241 (1969). - 8. Report of the Commission on Enzymes of the International Union of Biochemistry in Comprehensive Biochemistry, Band 13, Herausg. von M. Florkin und E. H. Stotz, Elsevier Publ. Comp., New York, S. 5 (1964). - 9. Schrwara, H. W., Ärztl. Lab. 17, 340 (1971). - 10. Frred, R. und J. Hoeflmayr, Ärztl. Lab. 11, 42 (1965). Dr. med. Hans-Walter Schiwara
216 Stade

Städtisches Krankenhaus 


\title{
Diagnostica
}





Merck hat alle Voraussetzungen geschaffen für die Vergleichbarkeit der Laborergebnisse in Klinik und Praxis durch standardisierte Enzymbestimmungen mit optimierten Tests:

\begin{abstract}
Alkalische Phosphatase (AP)
Cholinesterase (CHF)

Glutamat-Oxalacetat-Transaminase (GOT)

Glutamat-Pyruvat-Transaminase (GPT)

a-Hydroxybutyrat-Dehydrogenase (HBDH)

Lactat-Dehydrogenase (LDH)

Leucin-Arylamidase (sog. LAP)
\end{abstract}

Spezialprospekte „Merckotest Automatenpackungen”, "Merckotest" und "Merck-1-Test" senden wir Ihnen gern auf Anforderung zu.

E. Merck, Darmstadt 
DünnschichtChromatogramme gezielt entwickeln mit der CAMAG
VARIO-KS-Kammer

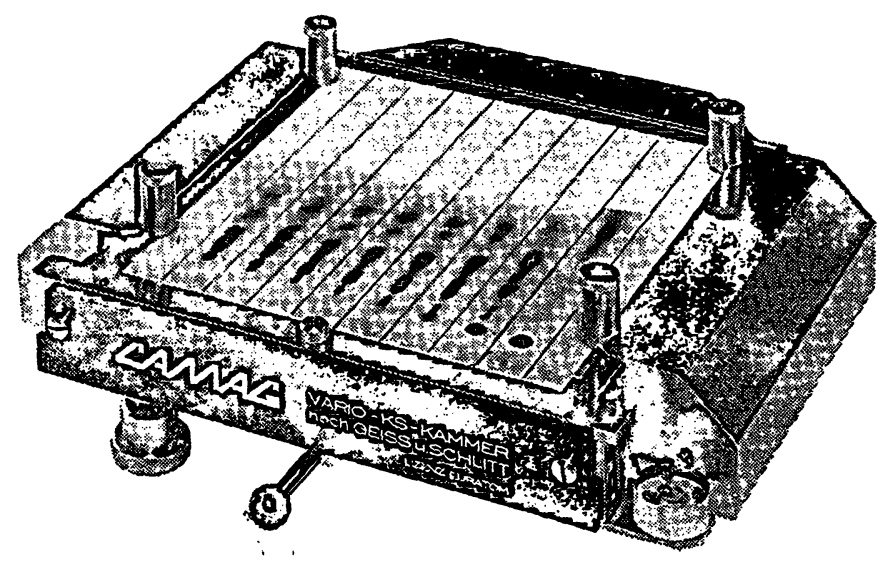

Reproduzierbare Chromatogramme besonders bei der quantitativen DC !

Entwicklung mit Schichtvorbeladung: optimale Trennergebnisse, vorausbestimmbares Trennverhalten.

Beeinflussung der Trenneigenschaften durch Längs- und Quergradienten.

Substanzklassenanalyse.

Ausbildung von Feuchtegradienten zur Überbrückung grosser Polaritätsunterschiede im Trenngemisch.

Durchlaufchromatographie.

Ausführliche Beschreibung in unserem Prospekt 251-400.

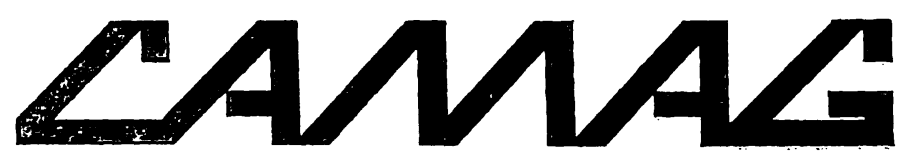

Homburgerstrasse 24 4132 Muttenz/Schweiz

Unser Zweigbetrieb in der Bundesrepublik:

1000 Berlin 45, Baseler Strasse 65

Führend in

Dünnschicht-Chromatographie Dünnschicht-Elekrophorese Hochspannungs-Elektrophorese

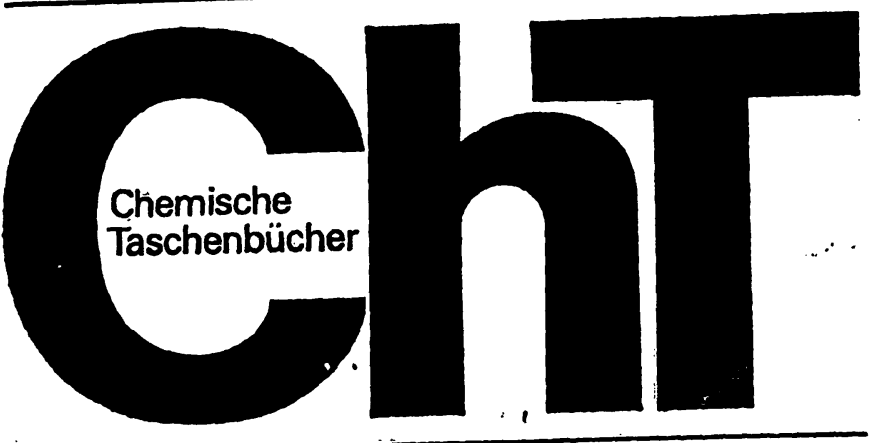

Soeben erscheint:

\section{Band 16 Detmar Beyersmann Nucleinsäuren}

Nucleinsäuren sind informationsübertragende Makromoleküle. Die Untersuchung der Nucleinsäuren mit chemischen, physikalischen und biologischen Methoden hat wesentlich dazu beigetragen, biologische Prozesse auf der Ebene der molekularen Strukturen und Reaktionen verständlich zu machen.

In dem vorliegenden Band werden zunächst in knapper Form die chemischen Eigenschaften der Nucleinsäuren und ihrer Bausteine beschrieben. Es folgt eine ausführlichere Darstellung der Konformationen, besonders von DNS. In den folgenden Kapiteln wird gezeigt, wie chemische und physikalische Eigenschaften die Grundlage für die biochemischen und biologischen Funktionen der Nucleinsäuren darstellen. Der Autor behandelt eingehend den enzymatischen Auf- und Abbau der Nucleinsäuren, die Rolle der Nucleinsäuren.bei der Übertragung der genetischen Information von Generation zu Generation und bei der Ausprägung genetischer Information in den Strukturen und Funktionen einer lebenden Zelle. Dabei wird besonderes Gewicht auf die Mechanismen der DNS-Replikation und die Eigenschaften des genetischen Code gelegt. In gedrängter Darstellung werden die Grundprinzipien der Nucleinsäureübertragung von Zelle zu Zelle (u. a. durch Viren) sowie der Regulation der Nucleinsäurefunktionen dargestellt. Zum Schluß wird ein Überblick von Inhibitoren und Strahlen gegeben, die in die biologische Synthese und Funktion der Nucleinsäure eingreifen. Unter diesen Agentien sind wichtige Hilfsmittel für die Untersuchung der Nucleinsäurefunktionen. Therapeutica gegen bakterielle Infektionen oder Tumorwachstum sowie mutationsauslösende Substanzen.

Die Aufgabe dieses Taschenbuches ist die Vermittlung der Grundprinzipien der Struktur und Funktion der Nucleinsäuren. Da diese Kenntnisse bei der Untersuchung von Mikroorganismen gewonnen werden, beschränkt sich die Beschreibung der biologischen Rolle der Nucleinsäuren in dem vorliegenden Band weitgehend auf Vorgänge in Bakterien.

Chemische Taschenbücher. Band 16.

Hrsg. von W. Foerst und H. Grünewald.

1971. VIII, 192 Seiten mit zahlreichen Abbildungen und Tabellen. Broschiert DM 24,--.

ISBN: 3-527-25333-5 LC Catalog Card No.: 74-173362

VERLAG CHEMIE - GMBH

WEINHEIM/BERGSTR. 